\title{
INCREASE OF EFFICIENCY OF TRACTORS USE IN AGRICULTURAL PRODUCTION
}

\author{
Ilgiz Galiev, Camill Khafizov, Nail Adigamov, Rail Khusainov \\ Kazan State Agrarian University, Russia \\ drgali@mail.ru,fts-kgau@mail.ru,n-adigamov@rambler.ru, rail-1312@mail.ru
}

\begin{abstract}
The modern stage of development of agrarian production is characterized as a transition period in market relations. In turn market relations are characterized by crisis situations, especially at the beginning of formation of structure of economic activity of enterprises of agro-industrial complex. Increase of efficiency of tractors is directly connected with estimation of their condition and development of measures on maintenance of performance of agricultural works without refusal of tractor units, and also substantiation of volume of works of the planned period, providing working State of the equipment. Technical condition and techno-economic indicators of machines in the process of operation are constantly changing. These changes are caused by constant increase of wear of machine parts, violation of dimension circuits and conditions of contact in part mates. As a result, the technique goes from working state to non-working, which is accompanied by the emergence of tractor failures of various groups of complexity. The challenge is to prevent these failures. For this purpose the technique of estimation of a condition of tractors which consists in determination of level of ability to perform works is developed. The level of ability of the tractor to perform the work-the degree of compliance of the tractor status parameters with nominal values. Experimental researches on definition of dependences of level of ability of the tractor to performance of works and indicators of their reliability on the basis of which are received permissible and limit values of levels for the basic kinds of agricultural works.
\end{abstract}

Keywords: tractor reliability, tractor condition, operation efficiency, planning of mechanized works.

\section{Introduction}

Control of the tractor's ability to perform work, rational use of the resources of the machineTractor Park is a strategic and priority factor to increase its efficiency, because the park of agricultural machinery has a high Capital. The cost of the optimal fleet of agricultural machinery in the country is estimated at more than one trillion rubles [1]. Annually agricultural production sector consumes about $15.6 \mathrm{mln}$. tonnes of motor fuel. This component of agricultural production forms up to $40 . .60 \%$ of the final production costs [1]. Therefore, for agriculture management ability to perform work, the strategy of saving the resource of machines is vital, as a basis for ensuring a competitive policy of the agrarian sector of the national economy.

Despite the fact that the potential of domestic tractors is improving, there is a tendency to decrease the efficiency of their operation [2]. The main limiting factor of efficient use of tractors in agriculture remains the problem of management of tractor reliability, as agricultural production is influenced by production, natural and climatic conditions, i.e. depends on the conditions of economic activity [3].

The main factors of increasing the efficiency of tractors use are determined by the level of realization of the following measures aimed at intensification of agricultural production: energy supply of production technologies products; maintenance of tractors in a state of ability to carry out agricultural work. In this connection, it is necessary to solve the following tasks: to observe qualitatively and precisely the technology of cultivation of agricultural crops; increase the efficiency of tractors operation in agricultural production.

Tasks are solved by ensuring the functioning of tractors without failure of parts, that is, control of the ability to perform work.

\section{Materials and methods}

The general indicator of any agricultural work in soil treatment, which affects the reliability of the tractor, is the degree of not uniformity of engine loading. Moreover, there is a tendency-the greater the depth of processing, the greater the coefficient of unevenness, for example: For packing soil $\delta_{m}=0.06 \ldots 0.12$, and for plowing $-\delta_{m}=0.2 \ldots 0.6$ [2]. Obviously, if the engine is loaded unevenly during the agricultural work, then the other systems, the units experience dynamic loads, which is the reason of change of the wear intensity of the parts.

Based on the literary analysis and the real state of use of tractors revealed that the failure of the tractor's ability to perform the work can be expressed by three states: 
1. the tractor can not be used in the performance of a particular agricultural operation, that is, if the tractor is not able to perform any agricultural work due to the failure of the part, the tractor may remain capable of performing other agricultural operations, the execution of which is not related to the state of this part;

2. use of the tractor is possible, but there is a significant violation of the quality of agricultural work or the threat to the safety of the tractor driver, that is, the wear of tractor parts reached a value in which the likelihood of their failure or reduction of power is large;

3. further use of the tractor is impossible for economic reasons, that is, the specific costs, including the costs of carrying out repair and maintenance effects to maintain and restore the ability of the tractor to do the work, start to increase.

Based on the foregoing, it is possible to draw the following conclusions:

- not all tractor units determine its ability to perform work;

- not all units that determine the ability of the tractor to perform the work, have an impact on the quality of agricultural work, i.e. a tractor that is unable to perform one group of agricultural work, can perform other groups of agricultural operations, moreover, changing the composition of the unit (reducing resistance, changing the width of the assembly) can change the condition of the tractor to able to perform the job, for example: due to wear of mates, Parts and units the engine power has decreased by so much that the tractor cannot be coupled with the calculated number of harrows, but having removed a certain quantity of them it is possible to carry out agricultural work without occurrence of refusal.

Thus, we need an indicator that determines the degree of wear and tear of units and systems of the tractor, the possibility, if necessary, the distribution of tractors for agricultural work on the basis of its ability to perform work without failure parts.

An indicator of state of the art assessment - the level of ability of the tractor to do the job. The level of the ability of the tractor to perform work $\left(Y_{p}\right)$, is the degree of compliance of the parameters of the state of the tractor nominal values. The theoretical level of the tractor's ability to perform work can vary from 0 to 1 , which corresponds to, with equal to $0-$ it is assumed that the tractor is written off from the balance sheet of the economy; with equal to 1 - the tractor is in good condition and all diagnostic parameters have nominal values.

Thus, the ability and inability of the tractor to perform the work is characterized by formula (1):

$$
0<Y_{p}<1,
$$

Thus, the level of the ability of the tractor to perform work tends to decrease, and after the repair and maintenance actions to increase, stabilize and again to decrease during operation.

The results of the theoretical researches and the method of determining the level of the tractor's ability to perform the work are presented in the monograph [4]. Developed by US method of estimation of condition of tractors allow to carry out the differentiated approach in planning of use of technics which consists in a ghost in conformity of level of ability of the tractor to carry out work and planned volume Agricultural operations.

Realization of the above is possible only at presence of dependences of influence level of ability of the tractor to carry out work on reliability indicators at performance of various kinds of agricultural works. The task of the experiment was also to check the adequacy of these dependencies and the level of ability of the tractor to perform the work as an indicator reflecting the condition of the tractor.

Collection of information was carried out in the farms typical for the Volga zone of the Russian Federation in the direction of economic activity, climatic and soil conditions, in which the tractors perform a characteristic for the given area complex of agricultural works. Since the information should be collected in a short time, the data collection on reliability indicators is carried out by the method of surveys of accounting reports of farms and by the method of momentary observations [5].

The information collected with the help of the momentary observation method should provide for each farm, on average, the estimation of the following indicators: The parameter of the failure flow, the coefficient of readiness, the coefficient of technical use. 
In order to observe the widest range of changes in the technical condition of the objects, the tractors in the beginning, middle and end of repair periods were taken under supervision.

The collection of information in the operating conditions for the evaluation of the reliability of tractors was carried out in accordance with the branch standard [6]. Frequency of observations-at least 2 times a month.

The information on refusals was included in the observation sheets: the date of the tractor failure, the tractor's working hours from the beginning of the observations to the moment of the failure of the parts, the name of the failing unit, the short characteristic of the failure. With the characteristic of the tractor failures the recommendations of the branch standard were used [6].

Information from observational sheets was processed in accordance with the classifier of parts failure [6] and was reduced to the table, which indicated the diagnostic parameters of tractor units, levels of their ability to perform work at the beginning of observations, Number of failures of tractors $1,2,3$ groups of complexity. The experimental data were then processed using mathematical statistics methods.

\section{Results and discussions}

As a result of theoretical and experimental researches the dependence of change of failure parameter of different groups of complexity is obtained depending on level of ability of the tractor to perform work for main types of performed Operations, i.e. the degree of unevenness of engine loading.

The results of the dependency definition are shown in table 1. The obtained regression dependencies allow to evaluate the parameter of the tractor failure flow on the site of 1000 moto hour (mh) depending on the level of the tractor's ability to perform the work. Adequacy of the obtained dependencies was checked by comparing the parameters of the flow of tractor failures in the farms, which did not participate in the experimental studies with the data obtained from the formulas given in table 1 . With a probability of 0.95 , the confidence interval value for the failure stream parameter does not exceed $6 \%$ of the value obtained by these dependencies.

Using constraints of parameter change the tractor failure rate for the main types of agricultural works, depending on the level of the tractor's ability to perform work, the limit value of the level is revealed.

Table 1

\section{Dependence of parameters of failure of tractors on groups of complexity and level of their ability to carry out work}

\begin{tabular}{|c|c|c|c|c|c|}
\hline No. & $\begin{array}{c}\text { Type of } \\
\text { agricultur } \\
\text { al works }\end{array}$ & $\begin{array}{l}\text { Failure } \\
\text { comple- } \\
\text { xety } \\
\text { group }\end{array}$ & $\begin{array}{l}\text { The equation of the dependence of } \\
\text { the tractor failure parameter and the } \\
\text { level of ability to perform the work, } \\
10^{3} \text { per mh }\end{array}$ & $\begin{array}{l}\text { Cor- } \\
\text { relation } \\
\text { coef- } \\
\text { ficient }\end{array}$ & $\begin{array}{l}\text { Cor- } \\
\text { relation } \\
\text { coef-ficient } \\
\text { error [5] }\end{array}$ \\
\hline \multirow{3}{*}{1} & \multirow{3}{*}{$\begin{array}{l}\text { Ploughing } \\
\text { soil }\end{array}$} & I & $\omega=5.33 \cdot Y_{p}^{-0.444}-5.522$ & 0.63 & 0.14 \\
\hline & & II & $\omega=5.984-13.93 \cdot Y_{p}+8.46 \cdot Y_{p}^{2}$ & 0.49 & 0.16 \\
\hline & & III & $\omega=0.407-4.119 \cdot \log _{10} Y_{p}$ & 0.51 & 0.18 \\
\hline \multirow{3}{*}{2} & \multirow{3}{*}{$\begin{array}{c}\text { Soil } \\
\text { cultivation }\end{array}$} & $\mathrm{I}$ & $\omega=5.369 \cdot 0.053^{Y p}$ & 0.49 & 0.18 \\
\hline & & II & $\omega=4.264 \cdot 0.037^{Y p}$ & 0.62 & 0.17 \\
\hline & & III & $\omega=3.68 \cdot 0.0133^{Y p}$ & 0.65 & 0.15 \\
\hline \multirow{3}{*}{3} & \multirow{3}{*}{$\begin{array}{c}\text { Soil } \\
\text { harrowing }\end{array}$} & I & $\omega=4.944-12.124 \cdot Y_{p}+7.9 \cdot Y_{p}^{2}$ & 0.43 & 0.13 \\
\hline & & II & $\omega=3.667-9.549 \cdot Y_{p}+6.6544 \cdot Y_{p}^{2}$ & 0.67 & 0.14 \\
\hline & & III & $\omega=-0.302-2.42 \cdot \log _{10} Y_{p}$ & 0.54 & 0.19 \\
\hline \multirow{3}{*}{4} & \multirow{3}{*}{$\begin{array}{c}\text { Packing } \\
\text { soil }\end{array}$} & $\mathrm{I}$ & $\omega=1.808 \cdot Y_{p}^{-0.443}-1.789$ & 0.63 & 0.19 \\
\hline & & II & $\omega=1.205 \cdot Y_{p}^{-0.461}-1.241$ & 0.48 & 0.14 \\
\hline & & III & $\omega=0.813 \cdot Y_{p}^{-0.491}-0.925$ & 0.66 & 0.17 \\
\hline
\end{tabular}

The basis for determining the limit value is the failure of the details of the third group of complexity with a probability of 0.9 . However, performance of agricultural works is connected with expenditure of a resource, i.e. decrease of level of ability of the tractor to carry out work. In this 
regard, it is necessary to increase the limit values by the intensity of the decrease in the capacity of the tractor to perform work for this type of agricultural operation for the period up to the next maintenance № 3, that is, for $1000 \mathrm{mh}$. Using dependencies (table 1) the changes in the level of ability of the tractor to perform work for ploughing the soil (0.21), cultivation (0.15), harrowing (0.12), packing (0.09) are determined. The results are shown in table 2.

Table 2

\section{Limit and permissible values of the level of the tractor's ability to perform work for the main} types of agricultural work

\begin{tabular}{|c|c|c|}
\hline \multirow{2}{*}{$\begin{array}{c}\text { Type of agricultural } \\
\text { works }\end{array}$} & \multicolumn{2}{|c|}{$\begin{array}{c}\text { The values of the level of ability of the } \\
\text { tractor to do the job }\end{array}$} \\
\cline { 2 - 3 } & limit & permissible \\
\hline Ploughing soil & 0.46 & 0.67 \\
\hline Soil cultivation & 0.30 & 0.45 \\
\hline Soil harrowing & 0.26 & 0.38 \\
\hline Packing soil & 0.19 & 0.28 \\
\hline
\end{tabular}

After determining the level of the tractor's ability to perform work, depending on the planned volume of work, it is necessary to determine the required level value [7], the question of possible attraction of a tractor for a particular work on the basis of performance Operations without failure of parts.

The required value of the ability level of the tractor to perform the job is determined by the formula (2):

$$
Y_{p t}=Y_{p p i}^{\prime}+Y_{p d 1} \cdot X_{1}+Y_{p d 2} \cdot X_{2}+Y_{p d 3} \cdot X_{3}+Y_{p d 4} \cdot X_{4}
$$

where $Y_{p t}$ - the required value of the level of ability of the tractor to do the job;

$Y_{p d i}$ - the permissible value of the ability level of the tractor to perform the work for the ith operation;

$Y_{p p i}^{\prime}$ - the highest value of the tractor ability level to perform the work that is included in the work item for the planned period;

$X_{1}, X_{2}, X_{3}, X_{4}$ - accordingly, the share of plowing, cultivation, harrowing and packing of soil in the total amount of work for the planned period for a particular tractor.

After determining the required level of the tractor's ability to perform work and compare this value to the actual level, there may be a situation where some work may not be performed due to the fact that the state of the equipment is lower The required value of the tractor's ability level to perform the work.

When this situation occurs, the following ways of solving the problem are possible:

- to bring in compliance a condition of equipment with the required value of level of ability of the tractor to perform work, i.e. to increase it by carrying out repair and servicing works;

- to align the required level value with the actual level of the ability of the tractor to perform the work, i.e. to reduce the required level value to the level corresponding to the state of the tractor or to reduce the planned annual load

The first way to solve the problem is now being applied. To do this, it is necessary to identify the tractor units, which have the greatest potential to increase the level of their ability to perform the work [7].

The second way to solve the problem, to match the actual and required values of the level of the tractor's ability to perform the job, is to reduce this value to the actual. The realization of this consists in artificial reduction of the resistance of the Unit, i.e. reduction of the number of hulls, harrows, cultivating paws, etc. or reduction of the planned annual load of the tractor.

This method applies if the cost of loss of crops, due to non-observance of agrotechnical terms of operations, is higher than the costs associated with the operation of the tractor with fewer working bodies of agricultural machines or low annual work. 
The number of working bodies of the agricultural machine to be removed from the unit will be determined by the formula (3):

$$
n_{p o i}=\frac{\left(Y_{p t}-Y_{p f}\right) \cdot \sum_{i=1}^{n} W_{i} \cdot B_{k i}-W_{i} \cdot Y_{p d i} \cdot B_{k i}^{\prime}}{\left(Y_{p t}-Y_{p f}\right) \cdot B_{k i}^{\prime} \cdot \sum_{i=1}^{n} W_{i}},
$$

where $n_{p o i}$-number of working bodies for $i$-th agricultural machine, pieces;

$Y_{p d i}$ - the permissible value of the ability level of the tractor to perform work;

$Y_{p f}-$ the actual value of the tractor's ability to perform the work;

$B_{k i}-$ structural width of the $i$-th agricultural machine, m;

$B^{\prime}{ }_{k}$ - width of capture of one working organ of $i$-th agricultural machine, m;

$W_{i}$ - volume of agricultural work for $i$-th agricultural machine, mh.

\section{Conclusions}

1. The arguments about necessity of increase of efficiency of operation of tractors are given and the substantiation in necessity of the indicator which estimates ability of the tractor to perform work (level of ability of the tractor to carry out work $Y_{p}$ ).

2. The obtained results of experimental researches in the form of dependences of change of parameters of a flow of failures of the tractor of various groups of complexity at performance of basic kinds of agricultural works depending on level of ability of the tractor do the job. Checking the adequacy of these dependencies allows to conclude that with a probability of 0.95 the value of the confidence interval for the parameter of the failure flow, for tractors, not participated in the experiment, does not exceed $6 \%$ of the value obtained on these dependencies.

3. Based on the dependence of the change of the parameter of the tractor failure rate for the main types of agricultural work, depending on the level of the tractor's ability to perform work, the limit and permissible values of the level are revealed.

4. Using the presented formulas it is possible to pick up for each tractor the kind and volume of works for the planning period. Distribution of agricultural works on tractors depending on their condition, that is selection for each tractor the nomenclature of operations and their volume for the planned period, gives an opportunity to prevent occurrence of complex failures of the tractor, to plan and optimize the resource consumption, the most rational use of the technique in tense periods. This, in the end, increases the efficiency of tractors operation.

\section{References}

[1] Strategy of machine-technological support of production of agricultural products of Russia for the period till 2010. Publishing House of the Russian Agricultural Academy, 2003. 149 p.

[2] Mihlin V.M. Management of the reliability of agricultural machinery. Moscow: Kolos, 1984. $335 \mathrm{p}$.

[3] Khafizov K.A., Khafizov R.N., Adigamov N.R. The main directions of technical service development in the agricultural complex of Tatarstan. Herald of Kazan State Agrarian University. -Publishing House of Kazan SAU, vol. 9, 2014, № 4 (34), pp. 95-102.

[4] Galiev. I.G. Increase of efficiency of tractors operation taking into account conditions of their functioning. Kazan: Publishing House of Kazan State University, 2002. 204 p.

[5] Volkov M.K. Research and improvement of the methods of obtaining reliable information about the failures of agricultural machinery: Abstract of the candidate of technical sciences. Chelyabinsk, $1982.18 \mathrm{p}$.

[6] OST 70.2.8-82. Tests of agricultural machinery. Reliability. Collection and processing of information.

[7] Galiev I.G. Management of the equipment efficiency taking into account the conditions of agrarian production. Bulletin of the Kazan State Agrarian University, № 1 (5). 2007, pp. 87-88. 